Didáctica. Lengua y literatura

ISSN-e: 1988-2548

https://dx.doi.org/10.5209/dida.65950

\title{
Teatro para jóvenes: teoría y temática en la sociedad del siglo XXI
}

\author{
Antonio César Morón ${ }^{1}$
}

Fecha revisión: 15-01-2019 / Fecha aceptación: 30-04-2019

Resumen. El teatro para jóvenes sigue siendo un género poco tratado y menos estudiado por los investigadores, pues muchas veces es incluido dentro del genérico teatro infantil. Desde este artículo se establecerán una serie de perspectivas teóricas y temáticas que ayuden a definir y comprender la compleja existencia de un género al que en muchas ocasiones se le ha negado su misma posibilidad de existencia.

Palabras clave: Teatro para jóvenes; Sociedad; Postmodernidad; Siglo XXI; Identidad.

\section{[en] Theater for young people:theory and thematic on the society of XXI century}

Abstract. Theatre for Young People is still a little treated gender and less studied by the researchers, as many times is included within the generic Children's Theatre. A series of theoretical and thematic perspectives that help to define and understand the complex existence of a genre that on many occasions has been denied their same possibility of existence will be established from this article.

Keywords: Theatre for Young People; Society; Postmodernism; Twenty-first Century; Identity.

\section{[fr] Théâtre pour les jeunes: théorie et thématique dans la société du XXIe siècle}

Resumé. Le théâtre pour jeunes reste un genre peu traité et moins étudié par les chercheurs, car il est souvent inclus dans le théâtre générique pour enfants. À partir de cet article, nous établirons une série de perspectives théoriques et thématiques qui aideront à définir et à comprendre l'existence complexe d'un genre qui, à de nombreuses occasions, a été privé de sa possibilité même d'existence.

Mots-clés: Théâtre pour les jeunes; Société; Postmodernité; XXI Siècle; Identité.

Sumario. 1. Introducción: perspectiva teórica. 2. Marco terminológico y conceptual para un teatro específico. 3. Temáticas de interés para los jóvenes de las sociedades occidentales. 4. El reggaetón y otros mass media como ritmo de la juventud occidental del siglo XXI. 5. Conclusión

Cómo citar: César Morón, A. (2019). Teatro para jóvenes: teoría y temática en la sociedad del siglo XXI, Didáctica. Lengua y literatura, 31, 233-242.

\footnotetext{
1 Departamento de Didáctica de la Lengua y la Literatura

Universidad de Granada

acemores@ugr.es
} 


\section{Introducción: perspectiva teórica}

Desde que Aurora Díaz Plaja (1968) denunciara el escaso número de obras teatrales de carácter infantil editadas en comparación con la demanda de las mismas, el panorama al respecto no ha cambiado mucho, en el sentido de que, si bien la Literatura Infantil y Juvenil supone una edición media de entre ocho y diez mil títulos anuales, el género aludido sigue siendo una proporción realmente menor en comparación con la narrativa y con la poesía. Berta Muñoz Cáliz (2006) destaca que de esa producción anual, solo una treintena de títulos pertenecen a lo que podríamos denominar Teatro Infantil y Juvenil. Lo que no destaca esta investigadora es qué porcentaje de esta producción pertenece a la franja de edad que denominamos infantil y cuál a la que denominamos juvenil, dado que ambos periodos permanecen a menudo indiferenciados en literatura, quizás porque definir el momento en que se abandona la infancia para entrar en la adolescencia es ya, de por sí, complejo incluso para la investigación psicopedagógica especializada (Hurlock, 1980; Hopkins, 1986; Monedero, 1982). Si bien analizando las cifras de edad aportadas por los diferentes especialistas en la materia podemos concluir que el periodo de la adolescencia transcurre normalmente entre los trece y los veinte años, desde un punto de vista conceptual podría definirse, en palabras de Hurlock (extraídas de Lozano, 2012), como

un periodo de transición en el cual el individuo pasa física y psicológicamente desde la condición de niño a la de adulto. Es una suerte de entreacto entre las libertades del pasado y las responsabilidades y compromisos que vendrán. Empieza cuando el individuo accede a la madurez sexual y culmina cuando se independiza legalmente de la autoridad de los adultos (Hurlock, 1980, 15).

Establecer una diferenciación clara entre lo juvenil y lo infantil en literatura resultaría pues fundamental; sin embargo, en muchas ocasiones se habla a los adolescentes con un lenguaje y sobre unas temáticas que ya nada tienen que ver con sus gustos o intereses cotidianos. Lozano, siguiendo a Hopkins, nos expone en unas pocas líneas los diferentes procesos de transformación de la personalidad que experimentan los adolescentes y cómo esto podría afectar a sus gustos e intereses:

Lo definitorio de la adolescencia es el afán de originalidad, el nacimiento de la intimidad, la búsqueda de la identidad personal y la reformulación de sí mismo. Esto explicaría algunas conductas como la manera de vestir, la búsqueda de un espacio para estar a solas, el uso de un lenguaje propio e incluso algunas excentricidades. Los juicios valorativos definirán su autoestima futura, conformando el componente afectivo del autoconcepto. Asimismo, son características las emociones primarias - miedo, ira, inquietud-, estados de ansiedad y sentimientos de inferioridad, en la adolescencia temprana; rebeldía, introspección, así como la afirmación de la naciente personalidad en la adolescencia intermedia; y un mayor optimismo y ruptura del aislamiento anterior en la adolescencia tardía o edad juvenil, la etapa de las grandes decisiones para el proyecto personal de vida (Lozano, 2012, 47-48).

Es sintomático que habiendo sido tan estudiada la caracterización psicopedagógica de este periodo, nos encontremos en el campo de la Literatura una reflexión como la siguiente del dramaturgo Luis Matilla, quien considera el teatro juvenil algo de lo 
que "todos hablan pero nadie es capaz de definir de manera convincente" (Matilla, 2003, 5), y continúa:

Desde mi punto de vista no existe un teatro juvenil, sino espectáculos con problemática juvenil a los que deberían asistir los adultos, siempre que se trate de montajes rigurosos en los que se presenten algunos de los singulares conflictos a los que se enfrentan actualmente los adolescentes. Rara vez se ofrecen en nuestro país espectáculos comprometidos con el mundo de los jóvenes ni con las problemáticas que a ellos les afectan, por lo tanto me parece impropio hablar de un teatro juvenil a no ser que nos refiramos a las funciones que los teatros oficiales, abren a los colegios e institutos cuando la taquilla empieza a flojear. La única franja de edad en la que pueden encontrarse características peculiares que justifiquen plenamente la concepción de un teatro específico, es la comprendida entre los 0 y los 12 años. A partir de esa frontera al niño se le debe situar ante el repertorio dramático universal [...] (Matilla, 2003, 6).

Isabel Lozano muestra, sin embargo, a este respecto un tono bastante más optimista, estableciendo una perspectiva completamente diferente al destacar que el problema no residiría en la inexistencia de un teatro juvenil, sino en otro tipo de cuestiones completamente ajenas a la literatura y al arte teatral en sí, aunque directamente relacionadas con la posibilidad de existencia de ambos. La investigadora se refiere concretamente a la infraestructura de producción de los diferentes montajes de teatro para adolescentes, que "a diferencia de otros países de nuestro entorno, en España no hay ni salas específicas -sino de teatro infantil y juvenil sin matices-, ni suficiente oferta tampoco en este sentido" (Lozano, 2014, 30).

El Teatro Infantil ha gozado en España de estudios concienzudos y diversos como muestra la Historia crítica del Teatro Infantil en España, de Juan Cervera (1982). Sin embargo, aquello que pudiéramos denominar Teatro Juvenil permanece frecuentemente desdibujado, cuando no completamente disimulado o absorbido por el género infantil. Lo que se desprende de las palabras aludidas de Luis Matilla es precisamente esta idea: que lo juvenil y lo adulto se equiparan en temas y, por tanto, a partir de los 12 años, no se puede hablar de un teatro específico que no sea el referido a los distintos géneros y temáticas que se especifiquen en el teatro adulto. Es llamativa además la peculiar manera que tiene Matilla de negar incluso la posibilidad de existencia de ese teatro específico, refiriéndose al mismo como una especie de beneficencia interesada de los teatros oficiales que "abren a los colegios e institutos cuando la taquilla empieza a flojear". Si analizamos con detenimiento esta idea, tal y como la expone el dramaturgo y crítico, se llega a la conclusión de que el interés de los adolescentes debe ser el "repertorio dramático universal" y fuera de ahí no queda terreno posible para ellos. Aunque lo más curioso de todo es que a Luis Matilla no le falta razón, dado que se está limitando exclusivamente a describir una realidad. Lo que habría que dilucidar es cuánto abarca la realidad descrita por él: si su círculo más cercano, si el teatro madrileño o si todo el territorio nacional. Es muy habitual que, dada la capitalidad cultural que como industria se establece desde Madrid y ejerce una amplia influencia en el resto del España, los críticos y teóricos madrileños hablen de realidad como si su propia realidad fuese extensible a la del resto del país. Esta investigación pretende analizar la problemática existencia del Teatro Juvenil, distinguiendo un punto de vista más universalista y de carácter teórico, de un punto 
de vista más local. Razón por la que siempre que se emplee la palabra "realidad" o cualquier otro concepto que tenga carácter comprehensivo, será acotado adjetivalmente, evidenciando así que la realidad es siempre múltiple y los puntos de vista, diferentes, dependiendo de los factores socioculturales que intervienen siempre, aunque muchas veces de manera inconsciente, en el discurso.

Los objetivos fundamentales de este trabajo, a tenor de todo lo expuesto hasta el momento, son dos: por un lado revisar la compleja problemática de nomenclatura que se establece en torno a un género específico dirigido a una edad muy concreta que revela unos gustos e intereses propios. Por otro, evidenciar cómo se adaptan esos gustos e intereses propios a la sociedad occidental globalizada de nuestro tiempo. Y para llevar a cabo estos dos objetivos de manera satisfactoria, resulta imprescindible establecer una metodología a partir de la cual se utilicen fuentes que proceden de diferentes ámbitos. De este modo se conectará la reflexión de relevantes investigaciones dentro del campo de la psicopedagogía y la sociología, con la crítica teatral especializada y aquella reflexión que procede de los creadores mismos, especialmente directores y dramaturgos.

\section{Marco terminológico y conceptual para un teatro específico}

Como apunta Juan Cervera, uno de los problemas para establecer un desarrollo conceptual de un teatro juvenil estriba en la dificultad de separar ambas audiencias, o, dicho de otro modo, encontrar una especificidad clara que diferencie lo infantil de lo juvenil:

La adolescencia, como etapa de transformación profunda, bullente y proyectada hacia el futuro, demanda otra clase de literatura a la que se acomoda mal el adjetivo infantil, pese a su uso corriente. Este adjetivo no recoge el intento de despegue de la infancia que entraña la adolescencia. Pero la rutina y tal vez más la carencia de un adjetivo que denote la condición de literatura para adolescentes ha hecho que se mantenga también para ésta la denominación de literatura infantil e incluso, a nuestro juicio, abusivamente, la de juvenil. Salta a la vista que no podemos aventurarnos a hablar de una literatura adolescente sin exponernos a que el adjetivo contamine peligrosamente y peyorativamente el sustantivo literatura [...] Pero lo más complejo es que entre la literatura para niños y la literatura para adolescentes no existe una frontera definida, hecho que no debe sorprender si se tiene en cuenta que la evolución psíquica del adolescente experimenta idénticas fluctuaciones y titubeos (Cervera, 2003, 7-10).

Dentro del ámbito norteamericano se han venido utilizando dos términos similares y que responden a las mismas siglas, si bien uno de ellos se genera y reproduce hacia los años 90 y el otro en pleno siglo XXI. Así, las siglas TYA responden a "Theater for Young Audiences" (Teatro para Jóvenes Audiencias) o "Theater for Young Adults" (Teatro para Jóvenes Adultos) (Van de Water, 2017, 28). Esta flexión terminológica responde exclusivamente a la dificultad que tienen las sociedades occidentales en la actualidad para establecer la frontera tanto psicológica como social que separa el estadio de lo juvenil de aquellos que están mucho mejor delimitados, como son lo infantil y lo adulto. Recordemos que, tal y como establece la directora 
Loreto Cruzat, siguiendo a Jean Piaget, "el pensamiento abstracto no se desarrolla [solo] hasta los 18 o 21 años, sino durante toda la vida" (Cruzat, 2017, 217); lo que la lleva a considerar que, si bien capta la mirada de los niños idear efectos sorpresivos sobre el escenario, porque su atención "está ligada a una estética visual y a un ritmo que debe cambiar constantemente", en los jóvenes

[...] ya no necesitamos idear recursos especiales, debemos concentrarnos, sí, en producir un espectáculo de calidad artística, igual como lo hacemos cuando entrenamos dentro del circuito teatral, en una sala para un público general. Debemos incentivar y estimular el pensamiento abstracto de los jóvenes, que está en pleno desarrollo para que cuando sean adultos sean personas con criterios formados capaces de deducir, de leer entre líneas, de imaginar (Cruzat, 2017, 218).

Si resulta más o menos fácil desde un punto de vista procedimental y casi de sentido común separar lo rigurosamente infantil de estas otras dos etiquetas, no resulta tan sencillo, sin embargo, separar temáticamente aquello que es juvenil de lo que es adulto. Ejemplos de sagas de best sellers como los de J.K. Rowling o E.L. James demuestran que el espectro de compradores potenciales de los mismos escapa al intento de encorsetamiento en férreas etiquetas, sugiriendo que las leyes del mercado y las de la ciencia psicopedagógica no siempre coinciden en sus formulaciones; y que son las del mercado siempre mucho más inmediatas, menos teóricas y, por tanto, más palpables, lo que les da la impresión de estar mucho más acordes con la realidad del público lector.

\section{Temáticas de interés para los jóvenes de las sociedades occidentales}

Resulta interesante la encuesta que Marianna Metsälampi realiza a un grupo de adolescentes y jóvenes finlandeses de entre 11 y 18 años. En respuesta a la pregunta “¿Qué clase de obras te gustaría ver?”, la autora saca las siguientes conclusiones acerca de las respuestas recibidas:

Lo que los niños en Finlandia les gustaría ver es comedias con música que traten, preferentemente, sobre temas actuales. Intenté hacer una mezcla con las respuestas y esto es lo que obtuve: comedias musicales que reflejen la crisis de la inmigración en Europa. La diferencia entre los mayores y los más jóvenes fue clara: para los jóvenes (11-12 años) es importante que la historia fuera conocida. Sus obras favoritas eran principalmente las mimas historias que Disney utiliza en sus películas; por ejemplo, mencionaron el Rey León y Peter Pan. El teatro es entretenimiento para los niños, tiene que hacerlos reír y tiene que ser grande y espectacular, como una película. Los adultos jóvenes (17-18) quieren piezas que sean versátiles, en las que haya felicidad y dolor y que despierten diferentes emociones. Los mayores, en mis encuestas, prefieren algo que los haga pensar cuando ven un espectáculo. Deberían tratar, de alguna forma, temas personales y también sociales. También les gusta el humor y la música en los espectáculos. Aquellos que hacen teatro prefieren las obras que tienen diálogo con temas sobre el mundo actual y que no son tan obvios. No quieren ver viejos clásicos hechos tradicionalmente, aunque están interesados en las versiones modernas. Si mencionaron obras en la encuesta, 
fueron de teatros de la ciudad, de Broadway o de Londres. No nombraron muchos otros. ¿Cuánto afectan los programas de los teatros de las ciudades la imagen y la expectativa de la gente joven respecto al teatro? En su repertorio hay musicales y comedias. Las obras teatrales también están conectadas con lo que los niños ven en la TV o en las películas (Metsälampi, 2017, 120-121).

En una sociedad globalizada como la que vivimos dentro del mundo occidental, las respuestas de estos jóvenes y adolescentes finlandeses pueden ser perfectamente exportables a un país como España ${ }^{2}$. Especialmente si analizamos en profundidad la cita e intentamos extraer algunos paradigmas sociológicos de verdad, en los que podamos reconocernos como sociedad:

a. Los adolescentes comienzan a primar más el pensamiento que el entretenimiento.

b. La dimensión psicológica de la identidad (¿quién soy?) y su fórmula emparentada sociológicamente de la ideología (¿qué opino?) son las herramientas básicas para su empoderamiento.

c. Gusto por el desafío intelectual: los adolescentes perciben que es su capacidad de razonamiento crítico lo que los separa de los niños.

d. Gusto por la comedia.

e. Búsqueda de la novedad frente a la reiteración de lo tradicional.

f. Fascinación por la moda y la publicidad (de ahí el gusto por los musicales o todo aquello que aparece en TV).

Por su parte, la profesora Lita Llagostera (2017) ha dado sin duda con una de las claves fundamentales para entender las demandas de los jóvenes y adolescentes del siglo XXI. Adentrándose en el campo de la Sociología a través del concepto de lo líquido aplicado a los entresijos de la vida postmoderna, destaca así la profesora la siguiente cita de Zygmunt Bauman:

Los vínculos humanos son cada vez más frágiles y se aceptan como provisionales. El joven adolescente percibe que a la brevedad [sic] se va a ver expuesto a los vaivenes del mercado laboral [...] La exposición de los individuos a los caprichos del mercado laboral y de bienes suntuarios premia las actitudes competitivas, y en contadas ocasiones se apuesta al trabajo en equipo. Se excluye todo aquel individuo al que se abandona o elimina una vez que se han agotado sus beneficios (Llagostera, 2017, 208).

Esta investigadora concluye que "El mundo globalizado aguijonea al adolescente mientras trata de ubicarse en su propio "yo" en relación con pares, padres, familia-

2 Después de un análisis concienzudo de decenas de obras teatrales escritas y publicadas casi todas ellas en España durante la primera década del nuevo siglo, Isabel Lozano destaca algunas de las temáticas que aparecen en las mismas y que se desmarcan definitivamente de lo infantil: "Con estos protagonistas adolescentes se plantean dramas sobre la efímera felicidad, cómo cumplir los sueños, la elección profesional y el deseo de éxito, la correcta elección de pareja, los falsos amores y amistades, la redención a través del amor, la diferencia de edad en las relaciones, la homosexualidad, el respeto a los demás, la justicia social, sobre los comportamientos moralmente dignos, la imagen corporal, las presiones de grupo, las actitudes egoístas con los padres, las conductas hedonistas, las tribus urbanas, el alcohol o las drogas y la sexualidad" (Lozano, 2014, 24). 
res" y, en definitiva, esto lo lleva a una crisis de identidad ante la confusión que experimenta ante el mundo. De ahí que posteriormente destaque en el mismo artículo una cita de Santiago García-Tornel acerca del mundo que le preocupa al espectador adolescente:

La globalización, los movimientos migratorios, los medios de comunicación, las tecnologías del conocimiento, la educación, la natalidad, el aumento de enfermos crónicos y personas de la cuarta edad, la crisis económica y los dramáticos cambios en la estructura familiar suponen una nueva concepción de nuestro entorno y, para algunos, una difícil adaptación o aceptación. La pregunta esencial es cómo estos cambios van a afectar a la población adolescente, qué nuevos retos vivirán y con qué recursos y herramientas van a superarlos (Llagostera, 2017, 209).

La crisis de identidad definitivamente se ha convertido en una de las problemáticas más acuciantes de la sociedad postmoderna o líquida occidental. La violencia y la frustración resultan una temática que seduce a la juventud occidental del Siglo XXI (Bauman, 2013, 2016). No solo en el teatro, sino también en otro tipo de productos artísticos como el cómic, los videojuegos, la novela o el cine podemos obtener títulos que confrontan esta afirmación. Concretamente referido al espacio cinematográfico, por la gran influencia que la cultura audiovisual -y concretamente este género- posee entre el mundo de los jóvenes, conviene mencionar al hilo de todo lo que venimos exponiendo una película que, casi al inicio del presente siglo, el cineasta estadounidense David Fincher - de la mano del guionista Jim Uhls y basada en una novela de Chuck Palahniuk- presentó con un extraño título y una temática singular, que había de convertirse en referencia de toda la juventud de aquel momento: Fight Club (Fincher, 1999).

En muchas ocasiones, el desarraigo que se produce por múltiples vías que tienen su origen fundamentalmente en el desapego familiar, en una lucha por reivindicar y empoderar lo nuevo de la juventud frente a lo viejo de los padres, adquiere dimensiones violentas con las que cada día se encuentran en los centros educativos los equipos de psicopedagogos.

\section{El reggaetón y otros mass media como ritmo de la juventud occidental del siglo XXI}

El dramaturgo, director de escena y crítico, Enrique Olmos de Ita, se plantea esta profunda separación que existe entre los adolescentes del mundo actual con los adultos de sus mismas sociedades; y lo hace en torno al gusto de los jóvenes de medio mundo por el reggaetón, como punto de encuentro estético musical, mientras está cargado este ritmo de desprestigio entre la generación adulta. Así, el crítico afirma que

Al indagar, con mínima profundidad, en la letra de las canciones más famosas del reaggaetón que viajan entre las discotecas de ambos países [España y Méjico] y otros muchos de la lengua castellana, es evidente que estamos frente a un fenómeno de involución, no solo rítmica sino discursiva, pues las letras de las canciones son claramente machistas, lúbricas hasta la literalidad [...] Los jóvenes de ahora 
buscan con mayor inmediatez el contacto con el otro, abominan el cortejo y prefieren la literalidad a la metáfora. Me pregunto, ¿quién soy yo para juzgar a los consumidores de este tipo de música? ¿Puedo parecer el inquisidor de otros tiempos? Recordemos que también fueron juzgados moralmente, con alto menosprecio, el rock and roll, el blues o el heavy metal (Olmos de Ita, 2017, 289-290).

Es interesante observar cómo este dramaturgo especializado en teatro para adolescentes ejerce un discurso crítico con la estética musical que lleva a bailar a los jóvenes de medio mundo, para después hacer un ejercicio reflexivo de autocrítica y preguntarse si no estará él mismo convirtiéndose en un "inquisidor de otros tiempos". Coincido con este dramaturgo en la idea de que aquí existe una de las claves del problema del teatro hecho para jóvenes: el estar hecho desde los adultos, sin respeto ni empatía por los gustos concretos de su época, y, sobre todo, cargado de un didactismo educativo muy explícito que a los adolescentes les molesta sobremanera, porque se sienten tratados como niños, cuando ya su infancia ha pasado para no volver jamás, y así "desde esa miopía intelectual tan paradigmática, se programan los teatros, se eligen los contenidos, y los artistas articulan la mayoría de las veces propuestas cursis, inexpresivas y llenas de moralejas edificantes" (Olmos de Ita, 2017, 291). Olmos de Ita sigue cuestionándose a continuación algo evidente:

¿Cómo pretendemos hacer teatro para este público específico sin conocer a fondo Internet, los videojuegos, la literatura del cómic, las redes sociales, los programas de televisión y la música de esta generación? ¿Cómo hablar con los jóvenes que pueden seguir guerras televisadas, atentados múltiples, barbarie comercial y nosotros queremos que durante una hora se enfrasquen en silencio en el dilema de Romeo y Julieta? Sin conocer sus referentes, solo los llevaremos al aburrimiento. Hablando con y desde su contexto evitaremos ese perfil censor de quien escucha reggaetón y lo abomina, simplemente porque lo desconoce (Olmos de Ita, 2017, 291).

Teniendo en cuenta todas las consideraciones expresadas en los últimos párrafos, se hace quizás más patente la conclusión provisional que la profesora Lita Llagostera afirma en su artículo de forma contundente:

El Teatro para el adolescente debería ser aquel que lo induzca a entender algunos aspectos de la vida adulta, que despierte su curiosidad y le genere interrogantes. Estos espectáculos le permitirán conocer las particularidades del mundo globalizado. El dramaturgo de la postmodernidad puede a la vez dar a conocer tanto "su aldea" como exponer temas y conflictos universales (Llagostera, 2017, 210).

Esta idea de universalidad le lleva a ver en Casa de muñecas, La ópera de tres centavos y Woyzeck tres ejemplos de dramas que pueden ser estimulantes para la problemática de los adolescentes de nuestros días. Si bien el dramaturgo Olmos de Ita va un paso más allá y compara el discurso teatral para jóvenes que se hace en Méjico, frente al del resto de discursos que se llevan a cabo en español, para elevar el teatro, por las circunstancias específicas que está viviendo el país, a un "acto de urgencia y responsabilidad social" que convierte a Méjico en la mayor "potencia de producción 
de teatro para niños y jóvenes en nuestra lengua, oponiendo al modelo tradicional, la urgencia de rescatar a una sociedad devastada por el desgobierno y la violencia del narcotráfico". Y continúa:

Mi generación teatral ha comenzado a salir a las calles [...], a las escuelas, a las plazas públicas, para apropiarse de ellas a través de contenidos originales, sin moralejas y sobre todo encaminados a prodigar temas trascendentales y polémicos, que no siempre son bien recibidos por padres de familia y maestros, originando así una resistencia artística inédita. Temas como la violencia en el noviazgo, el embarazo no deseado y la interrupción del mismo, el abuso sexual en la infancia y en la adolescencia, la inexistencia de dios, el suicidio como elección, el maltrato escolar, la migración, el aislamiento, homosexualidad, bisexualidad y asexualidad son algunos de los temas que parte del teatro mejicano está tocando, llevando a las escuelas, a los teatros públicos, a los libros [...] (Olmos de Ita, 2017, 292).

Cualquiera de los temas citados por el director Olmos de Ita bastaría para tener a cualquier adolescente pegado a la butaca durante el tiempo necesario para hacerlo reflexionar. Porque son temas que se acercan a su realidad más inmediata. El problema de la desmotivación de los adolescentes por el mundo del teatro está, fundamentalmente, como muy bien ha destacado este director, en el intento de labor educativa, cuando no doctrinaria en algunas ocasiones, de unos adolescentes cuyos temas de interés son mucho más rebeldes y reivindicativos que los de los adultos; pues en ellos no se ha completado todavía la estructuración ideológica pequeño burguesa exigida desde nuestros estados del bienestar para ser ciudadanos ejemplares.

\section{Conclusión}

El mundo de los adolescentes resulta más creativo, más rebelde, más salvaje temáticamente, más abierto al cambio, a la experimentación artística, sexual y social, más abierto al futuro y con mayor perspectiva que el mundo de los adultos. Esta es la razón fundamental por la que resulta imposible establecer un decálogo de intereses culturales y prácticamente universales con respecto a los receptores de esta literatura específica, lo que obliga a los creadores e investigadores en la materia a estar continuamente variando sus posicionamientos innovadores y críticos. De manera que, si la expectativa de cambio es uno de los condicionantes que caracterizan a nuestras sociedades líquidas, tal y como se desprende de la lectura de Bauman, quizás sea lícito concluir que realmente es el mundo de los adolescentes el que marca la trayectoria de nuestras sociedades y las orientan hacia lo que serán mañana. ¿Cómo no traer todo esto al centro del interés cultural y artístico que, se supone, ha sido fabricado para ellos?

Cuando se deja de un lado el didactismo educativo, muchas veces panfletario, para afrontar los temas con valentía, enfrentándose directamente con la realidad, los autores, directores y público de este tipo de teatro son quienes están mejor habilitados para rebelarse y hacer crítica de la realidad presente, que, como estuviera en la consideración de Artaud cuando decía "El cielo se nos puede caer encima" (Artaud, 1976), era el fin último del nacimiento de este arte denominado teatro. 


\section{Bibliografía}

Artaud, Antonin (2011): El teatro y su doble. Barcelona: EDHASA.

Baudrillard, Jean (2001): Cultura y simulacro. Barcelona: Kairós.

Bauman, Zygmunt (2016): Modernidad líquida. Ciudad de Méjico: Fondo de Cultura Económica.

Bauman, Zygmunt (2013): Vida líquida. Barcelona: Planeta.

Butiñá Jiménez, Julia (1992): Guía de teatro infantil y juvenil español. Madrid: Asociación Española de Amigos del Libro Infantil y Juvenil.

Butiñá Jiménez, Julia, Muñoz Cáliz, Berta y Llorente Javaloyes, Ana (2000): Guía de teatro infantil y juvenil. Madrid: ASSITEJ / UNED.

Cervera, Juan (1982): Historia Crítica del Teatro Infantil Español. Madrid: Editora Nacional.

Cervera, Juan (2003): Lo infantil y lo juvenil en literatura. http://www.cervantesvirtual.com/ obra/lo-infantil-y-lo-juvenil-en-la-literatura--0/ [consulta: 2 agosto 2018].

Cruzat, Loreto (2017): "El teatro como elemento integral en el desarrollo del pensamiento creativo". En Boletín Iberoamericano de Teatro para la Infancia y la Juventud, ASSITEJ, 12, pp. 213-222.

Díaz Plaja, Aurora (1968): “El teatro, este género difícil de editar". En I Congreso Nacional de Teatro para la Infancia y la Juventud. Madrid: Editora Nacional, pp. 183-192.

Fincher, David (1999): El club de la lucha. Estados Unidos: Fox 2000 Pictures.

Jameson, Frederic (2016): Teoría de la postmodernidad. Madrid: Trotta.

Hopkins, Roy (1986): Adolescencia: años de transición. Madrid: Pirámide.

Hurlock, Elisabeth (1980): Psicología de la adolescencia. Barcelona: Paidós

Llagostera, Lita (2017): "El teatro y los adolescentes del siglo XXI". En Boletín Iberoamericano de Teatro para la Infancia y la Juventud, ASSITEJ, 12, pp. 205-212.

Lozano Palacios, Isabel (2012): Aproximación a la literatura dramática juvenil actual: definición, determinación del corpus y análisis. [Tesis doctoral dirigida por Manuel Pérez Jiménez]. Alcalá de Henares, Universidad de Alcalá de Henares.

Lozano Palacios, Isabel (2014): “Canon y teatro juvenil”. En López Criado, Fidel (ed. lit.): Literatura, cine y prensa: el canon y su circunstancia. Santiago de Compostela: Andavira, pp. 85-92.

Lyotard, Jean François (2000): La condición postmoderna. Madrid: Cátedra.

Matilla, Luis (2003): “Teatro para niños. Reflexiones de un autor". En Las puertas del drama. Revista de la Asociación de Autores de Teatro, Siglo XXI, 14, pp. 4-9.

Metsälampi, Marianna (2017): "Qué es el teatro para los adolescentes finlandeses". En Boletín Iberoamericano de Teatro para la Infancia y la Juventud, ASSITEJ, 12, pp. 115-124.

Monedero, Carmelo (1982). Psicología evolutiva y sus manifestaciones psicopatológicas. Madrid: Biblioteca Nueva.

Muñoz Cáliz, Berta (2006): Panorama de los libros teatrales para niños y jóvenes. Madrid: ASSITEJ.

Olmos de Ita, Enrique (2017): "Vamoh a pegarno como animaleh". En Boletín Iberoamericano de Teatro para la Infancia y la Juventud, ASSITEJ, 12, pp. 289-293.

Van de Water, Manon (2017): “Teatro para jóvenes en el siglo XXI: ¿Qué es? ¿Cómo es? ¿Para quién es? La meta-pregunta”. En Boletín Iberoamericano de Teatro para la Infancia y la Juventud, ASSITEJ, 12, pp. 25-34. 